\title{
"Bronchodilator" Action of Deptropine Citrate with and without Isoprenaline by Inhalation
}

\author{
M. C. S. KENNEDY,* B.A., M.R.C.S., L.R.C.P.
}

Brit. med. F., 1965,'2, 916-917

The pharmacological properties of 3-(10,11-dihydro- $5 \mathrm{H}$ dibenzo (a, d) cyclohepten-5-yloxy)-tropane citrate (BS 6987, now known as deptropine citrate or Brontina) have been described by Funcke et al. (1962). These authors found that deptropine citrate protected animals against experimental bronchospasm. They also found that it was active after both parenteral and oral administration, and that it had antihistamine and some atropine-like properties. After these laboratory investigations Scherrer (1962) treated 11 asthmatic patients with intramuscular deptropine citrate (1 to $2 \mathrm{mg}$. daily). He made a number of physiological measurements before treatment and at intervals after treatment, including vital capacity, indirect M.B.C., pneumotachogram, and lung compliance. Although the response varied greatly in individual patients he concluded that an intramuscular injection of 2 to $3 \mathrm{mg}$. of deptropine citrate resulted in a bronchodilatory effect, and that this effect was usually maximal two to six hours after the injection.

\section{Patients and Methods}

Twenty "asthmatic" individuals were chosen for investigation. All these patients from previous studies (Kennedy and Thursby-Pelham, 1964) were known to have a fairly consistent response to aerosol adrenaline or adrenergic drugs by inhalation. Objective physiological measures were made on these patients before and at half-hourly intervals after the inhalation of one of the aerosols listed below for three and a half hours after the trial inhalation. After three and a half hours a further inhalation of adrenaline hydrochloride was administered as a wet aerosol for two minutes by means of a Collison inhaler, and the final measurement was recorded 20 minutes later. The aerosols were dispensed from cartridges containing an inert propellant with the active drugs in a non-aqueous suspension. A valve mechanism attached to the cartridge delivered a standard dose through a detachable mouthpiece. Special records were kept of any untoward symptoms and of the pulse rate throughout this period of observation.

The physiological measure used for this investigation was the indirect maximum breathing capacity expressed in litres per minute (Ind. M.B.C., ${ }^{1}$ as described by Kennedy, 1953).

Cartridges were prepared to deliver the following aerosols: (1) deptropine citrate cartridges delivering $0.1 \mathrm{mg}$. of deptropine citrate per puff; (2) isoprenaline and deptropine citrate cartridges delivering $0.15 \mathrm{mg}$. of isoprenaline and $0.1 \mathrm{mg}$. of deptropine citrate; and (3) inert cartridges containing inert propellant alone.

Patients were given two puffs from the respective cartridge, thus the dose of the active ingredients given to each patient was double the dose listed above.

\section{Results}

The indirect M.B.C. and the vital capacity readings on the 20 asthmatic individuals before and at intervals after the inhalation of (1) deptropine citrate, (2) isoprenaline and deptropine citrate, and (3) inert propellant were tabulated.
The results were analysed in two ways: (1) to show the overall response of the group of 20 patients to the different inhalants, and (2) to show the response of each patient to the three different inhalations.

\section{Changes in the Mean Indirect M.B.C. of 20 Asthmatic Subjects}

An overall picture of the response to the different drugs under trial was obtained by plotting the average indirect M.B.C. values of the 20 patients as a percentage change of the pretreatment values (see Chart). The following general observations can be made from the curves obtained.

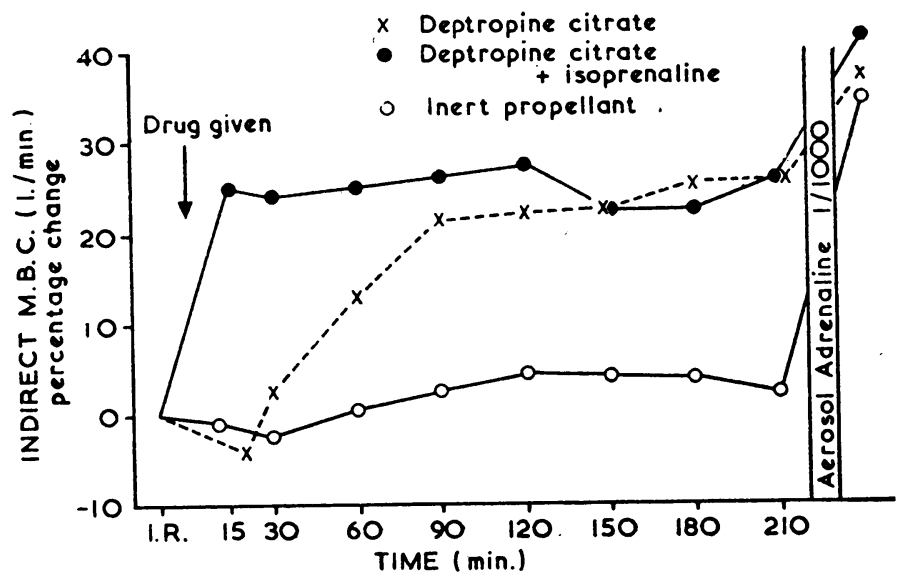

The percentage change of the mean indirect M.B.C. of 20 patients before and after the inhalation of (1) $0.2 \mathrm{mg}$. deptropine citrate; (2) $0.2 \mathrm{mg}$. deptropine citrate $+0.3 \mathrm{mg}$. isoprenaline; and (3) two puffs of an inert propellant (inhaler " $\mathrm{O}$ ")

(a) After the inhalation of deptropine citrate alone $(0.2 \mathrm{mg}$. there was an overall deterioration of roughly $4 \% \quad 15$ minutes after the inhalation. At 30 minutes the curve was showing a positive gain of $5 \%$, and progressively improved to $13 \%$ at 60 minutes, $22 \%$ at 90 minutes, and then flattened out. But after 90 minutes there was a further slight gradual gain, and the overall percentage improvement in the indirect M.B.C. at 210 minutes increased to $26 \%$.

(b) After the inhalation of deptropine citrate $(0.2 \mathrm{mg}$.$) com-$ bined with isoprenaline $(0.3 \mathrm{mg}$.) there was an overall improvement at 15 minutes of $25 \%$. Thereafter the overall group values remained roughly steady for the 210 minutes of observation with the curve showing a positive gain fluctuating between 22 and $27 \%$.

(c) After the inhalation of inhaler " $O$," when the patients received just the inert propellant, there was a deterioration of $0.7 \%$ at 15 minutes, and by 30 minutes there was a further deterioration of $2 \%$. Thereafter the graph showed a slight

* Department of Respiratory Physiology, City General Hospital, Stoke-on-Trent

${ }^{1}$ Indirect M.B.C. $=$ F.E.V.0.78 $\times 40$. 
positive gain varying between 1 and $4 \%$ during the 210 minutes of observation.

\section{Response of Individuals to the Three Different Inhalations}

The serial indirect M.B.C. readings of each individual after the three test inhalants have been scrutinized.

After the inhalation of deptropine citrate alone, the highest reading of 14 of the 20 patients occurred between 150 and 210 minutes ; the highest reading of the remaining patients occurred at 90 minutes (two patients), at 120 minutes (two patients), and at 60 minutes in one patient. The trial had to be discontinued after 15 minutes in one patient owing to severe asthma. Four individuals were substantially worse 15 minutes after the inhalation of deptropine citrate-that is, all these patients showed a drop in their indirect M.B.C. of $25 \%$ or more. None of these four patients, who showed this marked deterioration after the inhalation of deptropine citrate, showed a similar deterioration after the inhalation of the inert propellant.

After the inhalation of deptropine citrate and isoprenaline, the highest reading was observed at 15 minutes (six patients), at 30 minutes (two patients), at 60 minutes (three patients), at 90 minutes (one patient), at 120 minutes (three patients), at 180 minutes (two patients), and at 210 minutes (three patients). Roughly half the patients showed a sustained effect after reaching their peak indirect M.B.C. over the 210-minutes period of observation.

Fifteen minutes after the inhalation of the inert propellant there was only one patient who showed an improvement of $10 \%$ or more in the indirect M.B.C., most patients showed a slight drop. Peak readings of individuals after the inhalation was uniformly scattered throughout the 210 minutes of observation, but, as the group results showed, there was a general tendency for values to increase by 3 to $4 \%$ throughout the morning.

\section{Discussion}

The 20 asthmatic individuals reported in this investigation were included in an earlier comparative study on the effect of some adrenergic drugs and atropine methonitrate given by inhalation (Kennedy and Thursby-Pelham, 1964).
On comparing the result of this earlier study with the present investigation it is clear that the time-response curve after deptropine citrate is very similar to that obtained after atropine methonitrate. The earlier investigation showed that isoprenaline alone gave a time-response curve of short duration. However, isoprenaline combined with deptropine citrate gave an immediate and sustained effect which was very similar to the time-response curve observed in the present investigation after the inhalation of isoprenaline combined with deptropine citrate.

Deptropine citrate given alone produces nothing startling in the way of the usual atropine-like side-effects, but the asthma condition of four subjects investigated was worse immediately after the inhalation. In previous studies on the same 20 patients with atropine methonitrate alone, one individual showed a similar adverse response; after the inhalation of isoprenaline combined with deptropine citrate this same individual developed severe asthma at 30 minutes.

\section{Summary}

A comparative study of the effect on 20 asthmatic individuals of aerosols containing inert propellant, deptropine citrate alone, and deptropine citrate combined with isoprenaline is reported.

The inert propellant was inactive. Deptropine citrate aerosol alone is only effective in producing bronchodilatation after a latent period of one hour, whereas the combined deptropine citrate and isoprenaline aerosol is immediately effective and gives a sustained effect.

I am indebted to the staff of the Department of Respiratory Physiology for carrying out the investigations described in this report, especially Mr. James Booth, S.R.N., Mr. Peter Wilkes, S.R.N., Mr. Norman Curnock, S.R.N., Mrs. Sheila Clarke, S.R.N., and also to Mrs. K. Tattersfield, who prepared the Chart.

\section{REFERENCES}

Funcke, A. B. H., De Jonge, M. C., Tersteege, H. M., Mulder, D., Harms, A. F., and Nauta, W. Th. (1962). Acta physiol. pharmacol. Neerl., 11, 104 .

Kennedy, M. C. S. (1953). Thorax, 8, 73.

Kennedy, M. C. S. (1953). Thorax, 8, 734. Brit. med. F., 1, 1018.

Scherrer, M. (1962). Mededelingen Stichting Experimenteel Onderzoek Allergologie, No. VII.
In an attempt to provide some information of value in deciding which course to take, we have followed up the ovarian neoplasms treated by unilateral ovarian cystectomy or oophorectomy at Chelsea Hospital for Women during 1948-55. There were 100 such patients, permitting a follow-up ranging from 7 to 14 years. Of these, 63 were traced; mucinous cyst was found to be most common (24), and next the dermoid cyst (16). Benign neoplasms numbered 50, the remaining 13 being classified as malignant.

However, the distinction between a benign and a malignant cyst is not always clear-cut, but a distinction is important both clinically and histologically, since future management is governed by it. There are specimens of cyst in which only a small area of carcinoma is observed on examination, but a

\footnotetext{
- Consultant Obstetrician and Gynaecologist, St. George's Hospital, London. Formerly Chief Assistant, Chelsea Hospital for Women, London. † Consultant Pathologist, Chelsea Hospital for Women, London.
} 